\title{
O CONSUMO, O GOSTO, A PONTE E A CERCA: UM ESTUDO \\ EXPLORATÓRIO SOBRE GOSTO E REFERÊNCIAS ESTÉTICAS EM PROPAGANDAS DIRIGIDAS À BAIXA RENDA ${ }^{1}$
}

\section{Consumption, taste, bridge and fence: an exploratory study on taste and aesthetic references in advertisements directed at low-income}

\begin{abstract}
El consumo, el gusto, el puente y la cerca: un estudio exploratorio sobre los gustos y referencias estéticas en la publicidad dirigida a bajos ingresos
\end{abstract}

Jôse Fogaça ${ }^{2}$

\section{Resumo}

Desde a última década, o mercado emergente de baixa renda tem atraído a atenção de marcas e empresas, por seu grande potencial e pela ausência de conhecimento sobre essa parcela da população. A entrada desse contingente no mundo do consumo trouxe transformações de todas as ordens para diversos setores da sociedade e novos desafios e questionamentos para as marcas e para a publicidade. Este trabalho reflete sobre este fenômeno, dando foco à questão das particularidades culturais e da existência de demandas específicas desse mercado, especialmente no tocante às propagandas destinadas a esse público. O percurso inicia com a discussão do consumo como elemento definidor do pertencimento social, passa pelo tema do gosto estético de classes e termina com um exercício exploratório de análise de propagandas. Criam-se, nesse decorrer, os conceitos de consumo de inserção e consumo de ascensão.

Palavras-chave: baixa renda, consumo, gosto, propaganda, classes sociais.

\begin{abstract}
Since the last decade, the emerging market for low income has attracted the attention of brands and companies, for their great potential and lack of knowledge about this part of

\footnotetext{
${ }^{1}$ Artigo apresentado no GP Publicidade e Propaganda do XI Encontro dos Grupos de Pesquisa em Comunicação, evento componente do XXXIV Congresso Brasileiro de Ciências da Comunicação.

${ }^{2}$ Doutoranda do Programa de Ciências da Comunicação da ECA-USP. Mestre em Sociologia pela Unicamp. Pesquisadora junto ao GESC3 - Grupo de Estudos Semióticos em Comunicação, Cultura e Consumo. email: jofogaca@usp.br.
} 
O consumo, o gosto, a ponte e a cerca: um estudo exploratório sobre gosto e referências estéticas em propagandas dirigidas à baixa renda

de Jôse Fogaça

the population. The entry in this contingent world consumption brought transformations of all orders for different sectors of society and new questions and challenges for brands and advertising. This work reflects on this phenomenon, giving focus to the issue of cultural particularities and the existence of specific demands of this market, especially with regard to advertisements aimed at this audience. The course begins with a discussion of consumption as a defining element of social belonging, through the theme of aesthetic taste and class ends with an exercise exploratory analysis of advertisements. Creating, in this course, the concepts of insertion consumption and consumption rise.

Keywords: low income, consumption, taste, advertising, social classes.

\section{Resumen}

Desde la década pasada, el mercado emergente de bajos ingresos ha atraído la atención de marcas y empresas, por su gran potencial y la falta de conocimiento acerca de esta parte de la población. La entrada de contingente en lo mundo del consumo trajo transformaciones de todos los pedidos de los diferentes sectores de la sociedad y nuevas preguntas y desafíos para las marcas y la publicidad. En este trabajo se reflexiona sobre este fenómeno, concentrándose en la cuestión de las particularidades culturales y la existencia de demandas específicas de este mercado, especialmente en lo que respecta a los anuncios dirigidos a este público. El curso comienza con una discusión sobre el consumo como un elemento definitorio de la pertenencia social, a través del tema del gusto estético y la clase termina con un ejercicio de análisis exploratorio de los anuncios. Crease, en este curso, los conceptos de consumo de inserción y del consumo de ascensión.

Palabras-clave: bajos ingresos, el consumo, el gusto, la publicidad, las clases sociales.

Desde o lançamento de A Riqueza na Base da Pirâmide de C.K. Prahalad em 2004, os olhos do mundo se voltaram para a população de baixa renda, dando um novo sentido a ela. A publicação contribuiu para que essa parcela da população fosse percebida não mais como uma massa de não consumidores e deixasse de ser desprezada pelos empresários - os quais partilhavam do entendimento corrente de que a responsabilidade por tal contingente estava no âmbito público e governamental e não na esfera da produção privada. 
O consumo, o gosto, a ponte e a cerca: um estudo exploratório sobre gosto e referências estéticas em propagandas dirigidas à baixa renda

de Jôse Fogaça

A ideia de que o setor privado poderia ter um papel crucial a desempenhar na diminuição da pobreza global e que poderia ser possível erradicar a pobreza com lucro inspirou diversas ações de grandes empresas, evidenciando as oportunidades comerciais que esse novo mercado propiciava.

Mundialmente o mercado de consumo emergente compunha-se, nessa época, de 2,6 bilhões de pessoas, tendo crescido para algo em torno de 4 bilhões até 2009, a Ásia concentrando 60\% desse volume (PRAHALAD, 2010: 29). Esse crescimento é claramente percebido no Brasil com a entrada de 39,5 milhões de pessoas no mundo do consumo desde 2003, o que desfigurou a conhecida pirâmide social, alargando a fatia intermediária e a classe C, que já ultrapassa os $50 \%$ da população brasileira. São estas as pessoas que a estabilidade econômica transformou em consumidores, formando um contingente com mais força de compra que as classes A e B juntas. (FUNDAÇÃO GETÚLIO VARGAS, 2011; CETELEM BGN, 2011)

Assim, o interesse por esse poderoso mercado é observado em todos os setores e áreas no mundo e no Brasil. As marcas empenham-se em conhecer o novo consumidor, investigando, observando, envolvendo-se em seu cotidiano, mergulhando em seu mundo e em suas aspirações. Diversos estudos são desenvolvidos com esse objetivo, de todos os tipos - quantitativos de grande espectro, qualitativos com imersões nas casas dos consumidores -, municiando as empresas e as marcas para que possam desenvolver produtos e serviços que atendam às demandas específicas da classe emergente.

Mas há demandas específicas? O que há de tão diferente com essa parcela que na verdade já é a maioria da população brasileira? Trata-se de um nicho ou do próprio mercado? Há uma maneira especial de falar com estes consumidores emergentes? Como isso se traduz na publicidade?

Este trabalho pretende explorar estes questionamentos e está dividido em 3 partes. A primeira trata de pensar o consumo como chave para o reconhecimento social na sociedade contemporânea. A segunda destina-se à discussão sobre a questão do gosto e sua relação com as classes sociais. A terceira propõe uma nova conceituação e realiza um exercício exploratório de observação e análise de propagandas.

\section{CONSUMO E CONTEMPORANEIDADE - OU A PONTE PARA A SOCIEDADE DE CONSUMIDORES'}


O consumo, o gosto, a ponte e a cerca: um estudo exploratório sobre gosto e referências estéticas em propagandas dirigidas à baixa renda

de Jôse Fogaça

Consumir é fator essencial na definição de pertencimento à sociedade contemporânea, uma vez que esta se define pela centralidade desse fenômeno - o consumismo, como veremos a seguir - e a entrada no mundo do consumo é, no contexto da contemporaneidade, um momento de passagem, um ritual de inserção na própria sociedade.

Pensemos nos termos em que o faz Bauman (2008): a sociedade atual é caracterizada por ser a "sociedade de consumidores", essa sociedade que

\begin{abstract}
"interpela" seus membros (ou seja, dirige-se a eles, os saúda, apela a eles, questionaos, mas também os interrompe e "irrompe sobre" eles) basicamente na condição de consumidores. Ao fazê-lo, a "sociedade" (ou quaisquer agências humanas dotadas de instrumentos de coerção e meios de persuasão ocultos por trás desse conceito ou imagem) espera ser ouvida, entendida e obedecida. Ela avalia - recompensa e penaliza - seus membros segundo a prontidão e adequação da resposta deles à interpelação. Como resultado, os lugares obtidos ou alocados no eixo da excelência / inépcia do desempenho consumista se transformam no principal fator de estratificação e no maior critério de inclusão e exclusão, assim como orientam a distribuição do apreço e do estigma sociais, e também de fatias da atenção do público. (BAUMAN, 2008: 70).
\end{abstract}

O conceito de "sociedade de consumidores" (assim como os demais termos assinalados entre aspas neste parágrafo) é um tipo ideal criado por Bauman (2008), nos moldes weberianos, para designar uma sociedade caracterizada pelo "consumismo" e que teve como precursora a "sociedade de produtores" - o principal modelo societário da fase "sólida" da modernidade (BAUMAN, 2008: 42).

Segundo Bauman (2008), a "sociedade dos produtores" tem motivadores de consumo completamente distintos da "sociedade de consumidores". É na "sociedade dos produtores" que o conforto e o respeito podem ser tomados como os principais impulsionadores dos desejos e anseios para o consumo, apontando para "o desejo humano de um ambiente confiável, ordenado, regular, transparente e, como prova disso, duradouro, resistente ao tempo e seguro". Esta sociedade, basicamente orientada para a segurança, está inserida na era do "tamanho é poder" e do "grande é lindo" (BAUMAN, 2008: 42).

Nessa era, amplos volumes de bens espaçosos, pesados, obstinados e imóveis auguravam um futuro seguro, que prometia um suprimento constante de conforto, poder e respeitos pessoais. A posse de um grande volume de bens implicava ou insinuava uma existência segura, imune aos futuros caprichos do destino. (BAUMAN, 2008: 42). 
O consumo, o gosto, a ponte e a cerca: um estudo exploratório sobre gosto e referências estéticas em propagandas dirigidas à baixa renda

de Jôse Fogaça

Em resumo, a promessa, nesta sociedade, era a da segurança em longo prazo - e não o desfrute imediato de prazeres; e tal promessa se materializava no consumo ostensivo de bens - a exibição da solidez e da durabilidade e não, vale repetir, na fruição de prazeres imediatos.

Ao se "derreterem" estas características desta fase da modernidade, ao mesmo tempo em que o consumo toma um lugar central e protagonista na cena social, emerge a "sociedade de consumidores" e o "consumismo" dela característico.

O conceito consumismo é bastante caro a Bauman, por ser ele não uma característica dos indivíduos, como é o consumo, mas um atributo da sociedade. O consumismo consegue transformar as vontades, os desejos e os anseios humanos na "principal força propulsora e operativa da sociedade, uma força que coordena a reprodução sistêmica, a integração e a estratificação sociais, além da formação de indivíduos humanos" (BAUMAN, 2008: 41)

Para que uma sociedade adquira esse atributo, a capacidade profundamente individual de querer, desejar e almejar deve ser, tal como a capacidade de trabalho na sociedade de produtores, destacada ("alienada") dos indivíduos e reciclada/reificada numa força externa que coloca a "sociedade de consumidores" em movimento e a mantém em curso como uma forma específica de convívio humano, enquanto ao mesmo tempo estabelece parâmetros específicos para as estratégias individuais de vida que são eficazes e manipula as probabilidades de escolha e conduta individuais" (BAUMAN, 2008: 41).

Assim, o consumismo caracteriza não o desejo da apropriação ou posse visando o conforto ou o reconhecimento de outros; este seria um desejo pertinente à sociedade dos produtores na fase sólida da modernidade com vistas na construção de um ambiente ordenado, regular, seguro, duradouro. Ao contrário, esse desejo de estabilidade acaba por se transformar num risco para esta sociedade marcada pelo consumismo, em que o imperativo é o imediatismo e a rápida substituição dos objetos destinados a satisfazer uma necessidade (BAUMAN, 2008: 44).

(...) o consumismo, em aguda oposição às formas de vida precedentes, associa a felicidade não tanto à satisfação de necessidades (como suas "versões oficiais" tendem a deixar implícito), mas a um volume e uma intensidade de desejos sempre crescentes, $o$ que por sua vez implica o uso imediato e a rápida substituição dos objetos destinados a satisfazê-la. (BAUMAN, 2008: 44). 
O consumo, o gosto, a ponte e a cerca: um estudo exploratório sobre gosto e referências estéticas em propagandas dirigidas à baixa renda

de Jôse Fogaça

Sendo o consumismo a força propulsora da sociedade, os "não iniciados" nesse jogo de (in)satisfação de desejos não podem pertencer completamente a ela. O consumo enquanto ato é então o fundador dessa relação e desse pertencimento.

Essa ideia remete a outra, a de que o consumo pode ser pensado como "ponte", trabalhada por Douglas \& Isherwood, em O Mundo dos Bens (2009).

Estes autores assumem o consumo nos termos de sua realidade cultural e coletiva, atribuindo a ele a função de dar sentido ao fluxo incompleto dos acontecimentos. Os bens seriam a "parte visível da cultura", os "acessórios rituais" do processo ritual de consumo (DOUGLAS \& ISHERWOOD, 2009: 112-114).

Nesta visão, o consumo tem por finalidade primária classificar pessoas e eventos e os bens materiais de servirem como "marcadores das linhas nas relações sociais", de comunicarem a posição social a que se pertence ou aquela que se deseja pertencer: "podem ser usados como cercas ou como pontes" (DOUGLAS \& ISHERWOOD, 2009: 36).

Esta função, atribuída ao consumo, de "fazer sentido", de ser "como um código" para traduzir as relações sociais, de "classificar coisas e pessoas", não é, obviamente, um fenômeno exclusivo desta sociedade contemporânea, mas tem nela a sua expressão máxima, impulsionada pelos meios de comunicação de massa e principalmente pela publicidade ${ }^{3}$.

Como bem enfatiza Everardo Rocha na apresentação do livro de Douglas \& Isherwood (2009), “ uma das funções essenciais da cultura de massa - com evidente ênfase na publicidade - na sociedade contemporânea é ser a instância que viabiliza este código ao comunicá-lo à sociedade.” (ROCHA apud DOUGLAS \& ISHERWOOD, 2009: 16)

\footnotetext{
${ }^{3}$ Como mostrado em outro lugar (MARTINS, 2011), confluindo com a análise de Douglas \& Isherwood (2009), McCracken (2003) afirma que a função comunicadora dos bens não se esgota em ser um mero emissor de mensagens; eles são um sistema de construção da cultura. E esse sistema é marcado por uma característica definidora: a qualidade móvel do significado. Segundo McCracken, o significado está "ininterruptamente fluindo das e em direção às suas diversas localizações no mundo social, com a ajuda de esforços individuais e coletivos de designers, produtores, publicitários e consumidores." (McCRACKEN, 2003: 99). Neste esquema, a publicidade e o sistema de moda constituem meios através dos quais o significado é investido no "código objeto" - eles movem o significado do mundo culturalmente constituído para os bens de consumo -, enquanto os rituais de consumo o transferem destes para o consumidor (McCRACKEN,2003: 113-120).
} 
O consumo, o gosto, a ponte e a cerca: um estudo exploratório sobre gosto e referências estéticas em propagandas dirigidas à baixa renda

de Jôse Fogaça

Evidencia-se aqui o papel social que a publicidade e a comunicação de massa exercem: a de socializadores para o consumo. Segundo o autor, o sistema publicitário:

(...) é aí o espaço particularmente privilegiado, pois ao reproduzir no plano interno (no mundo dentro do anúncio, por exemplo) a vida social, permite a definição de produtos e serviços como necessidades, sua explicação como modos de uso, e a confecção de desejos como classificações sociais. A cultura de massa - mídia, marketing, publicidade - interpreta a produção, socializa para o consumo e nos oferece um sistema classificatório que permite ligar um produto a cada outro e todos juntos às nossas experiências de vida. (ROCHA apud DOUGLAS \& ISHERWOOD , 2009: 17)

Nesse contexto, retomemos o objeto deste trabalho: o consumo das classes emergentes, aqui representadas pela "nova classe média brasileira". A entrada destas pessoas no mundo do consumo pode ser pensado como ponte, a ponte necessária e fundamental para a inserção na "sociedade de consumidores", fundando, na materialidade, o seu pertencimento a ela.

Mas pode também ser pensado como cerca, uma vez que distingue os novos consumidores dos seus antigos pares - os mais pobres e não-consumidores.

E aqui nos salta aos olhos o duplo efeito consubstanciado no movimento de entrada na sociedade de consumidores: o ato de consumo significa também o abandono de um "não-lugar" e a chegada a um novo lugar social, um novo status ou posição dentro dessa sociedade. Esse movimento é também o marco de uma trajetória temporal definindo quem se é hoje em relação ao seu passado (à antiga condição de pobreza e restrição), distinguindo-o desse passado e dos que a ele ainda pertencem, negando a semelhança ou proximidade com estes.

Estes dois lados da mesma trajetória - afirmação do lugar para onde se está indo e negação do lugar de onde se veio serão importantes para as considerações sobre as referências estéticas e gostos e serão retomadas no tópico seguinte.

Por ora, é preciso lembrar que, para funcionar como cercas e pontes, é necessário que os códigos do consumo sejam comunicados e esse papel é desempenhado pela publicidade e pela comunicação de massa. É preciso também fazer a nova pergunta: que códigos são comunicados?

\section{ACERCA DO GOSTO - OU A CERCA DO GOSTO}


O consumo, o gosto, a ponte e a cerca: um estudo exploratório sobre gosto e referências estéticas em propagandas dirigidas à baixa renda

de Jôse Fogaça

Até aqui, se bem cumpriu sua função, este trabalho apontou que a contemporaneidade é marcada pelo consumismo enquanto atributo social; que o consumo tem por função "fazer sentido", traduzir relações sociais através da materialidade, classificar coisas e pessoas; indicou ainda que a publicidade tem por sua vez, como função, a socialização para o consumo, isto é, difundir os códigos que constituem o sistema de consumo, indicando o que deve ser consumido, como e porquê. É a publicidade que se responsabiliza pela captação e expressão dos valores que se agregam às mercadorias (SANTAELLA apud PEREZ, 2004); é a publicidade - e também a moda - que move o significado do mundo culturalmente constituído para os bens de consumo (McCRACKEN, 2003).

Adentremos então nesse mundo culturalmente constituído no qual se serve a publicidade. O que nos interessa saber é, num primeiro momento: que valores são captados, que referências exprimem, a que remetem? Para então, num momento posterior, discutir: os valores expressos na publicidade destinada ao consumo de baixa renda são diferentes dos da publicidade em geral?

Não há como negar que cores e fartura são características imediatamente associadas ao popular. Também não há como negar que uma propaganda que se utiliza de códigos culturais extremamente eruditos não irá ressoar nos públicos de baixa renda. O que está em questão é o entendimento do que significam essas referências e por que ecoam de forma diferente nos diferentes grupos.

É tudo uma questão de gosto?

O primeiro passo aqui é entender que estão em jogo um “eu” e um “outro”. Há o "eu" que faz a propaganda para o "outro" e há o "eu" que vê a propaganda feita pelo “outro". Publicitários responsáveis pela criação de propagandas de grandes marcas e pessoas pertencentes às classes baixas, com alguma rara exceção, não habitam o mesmo mundo, não vivem no mesmo bairro, não freqüentam as mesmas escolas, não pertencem, em suma, à mesma classe social.

Waldenyr Caldas (2009), em Utopia do Gosto, nos dirige nessa reflexão, afirmando claramente que "o gosto obedece a uma lógica implícita na sociedade de classes: a lógica da estratificação social. Cada classe social possui seu universo próprio de valores. E o gosto estético é um deles." (CALDAS, 2009: 159).

Com essa constatação, reconhece-se que a cultura da classe burguesa, ou dominante (para utilizar os conceitos aplicados pelo autor dentro do paradigma 
O consumo, o gosto, a ponte e a cerca: um estudo exploratório sobre gosto e referências estéticas em propagandas dirigidas à baixa renda

de Jôse Fogaça

marxista) difere da cultura da classe proletária ou classes subalternas. Estas culturas, entretanto, não necessariamente estão em oposição, apenas são diferentes uma da outra e podem em alguns momentos influenciarem-se mutuamente. (CALDAS, 2009: 17).

Embora o autor aponte que essa influência pode se dar nos dois sentidos - o proletariado sendo influenciado pela cultura burguesa e a burguesia pela cultura proletária, na prática o que se vê é um movimento muito mais freqüente e intenso no primeiro sentido.

Entre outros valores burgueses que chegaram até o proletariado, mesmo antes do papel fundamental dos meios de comunicação de massa na disseminação desses, está o que é mais caro à análise de CALDAS (2009), por suas implicações na estética do gosto: o desejo de ascensão social.

É o fascínio que os valores da burguesia exercem sobre o proletariado (conforto, lazer, letras, artes, ciência, que não podem atingir, seja por não possuir capital ou não ter tempo livre para isso devido às prolongadas jornadas de trabalho) que impulsiona ao desejo de ascensão social.

CALDAS (2009) sugere ainda que o estilo de vida burguês já traz a ideia de refinamento, de elegância, de gestualidade moderada, leve e delicada como herança da nobreza, indicando que as origens na diferença de determinado patrimônio (obras, produtos, objetos etc.) origina o maniqueísmo do gosto, estabelecendo o que é o "mau gosto" e o que é "bom gosto". A burguesia, diz o autor, "apenas absorveu e reproduziu valores culturais e comportamentos estéticos da nobreza" e "tudo o que fosse consumido ou prestigiado pela nobreza inicialmente, e depois pela burguesia, seria considerado produto, objeto de bom gosto". (CALDAS, 2009: 23)

Com a burguesia industrial ganhando ares de nobreza, a ideologia da ascensão social ganhava ainda mais força, incitando de maneira crescente a vontade do proletariado de absorver os seus valores e, uma vez que não conseguia ascender socialmente de fato (como conseguiria a burguesia francesa através da revolução), ao menos na aparência ou superficialmente o fazia. Uma das maneiras de assimilação era através da imitação, tipo de consumo que, na sociedade de massas, seria chamado de kitsch. (CALDAS, 2009: 24).

Se por um lado é claro e evidente o desejo e as estratégias encontradas pelos proletários em assimilar ou simplesmente imitar os valores burgueses, o sentido inverso - o interesse dos burgueses em absorver valores proletários - é mais obscuro, por ser 
O consumo, o gosto, a ponte e a cerca: um estudo exploratório sobre gosto e referências estéticas em propagandas dirigidas à baixa renda

de Jôse Fogaça

menos freqüente. Mas também ocorre. Caldas (2009) cita o exemplo da difusão dos sallon bars entre as classes superiores inglesas, incorporando os valores culturais dos pubs, que são típicos do proletariado. Mas isso não quer dizer que adotou o gosto estético do proletário, ao contrário, imprimiu a esta "instituição cultural proletária" que é o $p u b$, o seu gosto de classe, seus valores burgueses refinados e austeros. (CALDAS, 2009: 41)

\begin{abstract}
Os estudos antropológicos mostram que a interpenetração cultural não é um fenômeno prejudicial à cultura. Assim, se a burguesia incorporou ao seu universo cultural valores da cultura proletária (o pub, por exemplo), isto não significa de forma alguma a destruição nem da cultura proletária nem dos seus valores estéticos. No início da Revolução Industrial, como nos dias atuais, o público burguês e o proletário mantém comportamentos muito diferentes, cada um de acordo com o seu universo. (CALDAS, 2009: 44)
\end{abstract}

Trazendo a discussão à luz do contexto brasileiro, pode-se claramente verificar a questão da interpenetração cultural e, ainda que de forma apressada, afirmar que esse é um fenômeno contundente em nossa identidade, marcada pela mixagem étnica e pelo passado colonial. Há, contudo, que se ressaltar que o tema, por ser de grande importância, deve ser tratado com mais vagar e profundidade, o que não nos cabe no âmbito deste trabalho.

O que cabe observar é que algumas marcas brasileiras como Havaianas e Sagatiba podem ser tomadas como exemplos da absorção de "instituições populares brasileiras", por assim chamar, na medida em que buscaram valores que são comuns a todos os estratos sociais brasileiros (o conforto e a descontração, no caso dos chinelos, o gosto pela bebida, no caso da cachaça), reinventando produtos até então destinados somente às classes C, D e E. Deram-lhe, entretanto, uma roupagem completamente nova em que são evidentes o refinamento e os valores das classes mais altas. Nas palavras de Perez (2004), ao citar o caso das Havaianas, “a campanha de reposicionamento (...) elevou o produto de um "simples chinelo" destinado às classes C, D e E para ícone de elegância, modernidade e diferenciação das classes A e B . (PEREZ, 2004: 117).

\footnotetext{
${ }^{4}$ Clotilde Perez, em Signos da Marca (2004) cita o caso do relançamento da marca Havaianas justamente como exemplo da função da publicidade de agregação de valor: "O caso das Havaianas é exemplar, pois se trata de um produto lançado pela Alpargatas em junho de 1962, que era metonímia da categoria até início dos anos 90. Depois disso (concorrência, novas alternativas para os consumidores etc.), usar as Havaianas passou a ser "atestado de pobreza". Nas palavras da própria empresa (Exame, fev. 2003), na estratégia de reconstrução (na verdade, ressurreição) da marca, nenhum "P" do marketing foi esquecido.
} 
O consumo, o gosto, a ponte e a cerca: um estudo exploratório sobre gosto e referências estéticas em propagandas dirigidas à baixa renda

de Jôse Fogaça

Mas devemos lembrar que o sentido mais comumente observado, a despeito da existência das interpenetrações (e da necessidade de estudá-las com mais profundidade no contexto brasileiro), é o que movimenta os valores das classes altas para as classes mais baixas, levados principalmente pela ideologia da ascensão social.

Caldas (2009) vai além e nos diz que há, nesse processo, também a negação do gosto da classe social de origem:

(...) Aqui a questão não é propriamente política (embora nas origens se possa dizer que sim) e, além disso, trata de problemas ligados à superestrutura social. É a negação da estética, do gosto estético da sua classe social, e de certo modo a negação da sua própria classe. Em contraposição, está claro, esse comportamento gera a afirmação do capitalismo. (CALDAS, 2009: 47)

Ainda que haja outros aspectos muito importantes para a discussão do tema na análise de Caldas (2009), como por exemplo a questão do gosto médio, o que coube trazer como contribuição a este trabalho, e deve ser enfatizado, foi a função do consumo na dimensão interior da sociedade, ou seja, da ascensão dentro da sociedade classes.

Se já havíamos evidenciado que o consumo pode ser a ponte para a inserção na sociedade contemporânea - a sociedade de consumidores -, aqui se evidencia que há um outro nível de inserção, que é o da entrada numa posição ou classe superiores. E, nesse ponto, é de nosso interesse propor, como tipificação para o debate acadêmico, uma nova conceituação.

\section{CONSUMO DE INSERÇÃO E CONSUMO DE ASCENSÃO - CONCEITUAÇÃO E APLICAÇÃO PRÁTICA}

Ao se pensar nas transformações ocorridas na sociedade brasileira desde a década passada, o que primeiro salta aos olhos é a massiva entrada de pessoas no mundo do consumo. Essa é a passagem da realidade da privação - marcada pelo impedimento de adquirir os bens materiais mais básicos - para outra realidade, a das possibilidades marcada principalmente pela aquisição dos bens maiores e fundamentais segundo os valores de nossa sociedade: a casa (própria), os móveis, os equipamentos

Após o reposicionamento, os investimentos em publicidade passaram a representar $12 \%$ das vendas do produto. (PEREZ, 2004: 117-118) 
O consumo, o gosto, a ponte e a cerca: um estudo exploratório sobre gosto e referências estéticas em propagandas dirigidas à baixa renda

de Jôse Fogaça

eletroeletrônicos, o acesso ao mundo digital. A este movimento chamaremos de consumo de inserção.

Entende-se por consumo de inserção uma condição caracterizada pela obtenção daquilo que, a exemplo do que vimos na sociedade de produtores, materializa a situação de prosperidade e de segurança. É nesta condição que se adquirem os bens materiais mais sólidos: a casa, os eletroeletrônicos (iniciando pela linha branca), os móveis, além daqueles que possibilitam encontrar e se relacionar com os grupos e indivíduos: o computador e o celular.

Como já mencionado, o movimento de inserção tem um duplo sentido, uma vez que marca também a negação da situação anterior de miséria e restrição. É, portanto, para aqueles que se encontram nesta condição que os signos de fertilidade, abundância, festa e cor mais devem ecoar.

Por outro lado, há que se pensar em outra condição, naquela em que o almejado não é a entrada inaugural no universo do consumo, uma vez que já são consumidores, mas em que almejam os valores de uma classe superior à sua seja através do consumo de bens materiais ou imateriais, seja através do consumo kitsch da imitação, mas que de toda forma evidencia o desejo de ascensão a uma determinada posição social via consumo de bens e valores. A este movimento chamaremos de consumo de ascensão.

Entende-se por consumo de ascensão uma condição caracterizada pela obtenção daquilo que irá significar a entrada numa posição ou classe superiores. É nesta condição que se adquirem os bens materiais mais dotados de valor simbólico e que as marcas ganham em importância.

No contexto deste trabalho, destinado a refletir sobre o consumo de baixa renda, esta condição de consumo estaria atrelada à ascensão à chamada nova classe média brasileira.

Certamente é de difícil apreensão a separação real entre as pessoas que estão em uma ou outra condição, ou seja, a constatação de evidências concretas de que um ato de consumo indica um movimento de entrada no mundo do consumo (o que a rigor significaria dizer que essa pessoa nunca comprou nada por si só) ou se indica um movimento ascendente rumo a uma melhor posição social, o que seria o mais comum. Como tipo ideal que é, a tipificação aqui construída (consumo de inserção e consumo de ascensão) nos serve como recurso metodológico para análise da realidade e deve ser assim considerada para os passos seguintes deste trabalho. 
O consumo, o gosto, a ponte e a cerca: um estudo exploratório sobre gosto e referências estéticas em propagandas dirigidas à baixa renda

de Jôse Fogaça

A partir desta tipificação é possível realizar um exercício exploratório relacionado a propagandas destinadas ao mercado alvo deste estudo. Para tanto, selecionou-se um grupo de imagens de diversos tipos de material publicitário (folheto de promoções, propaganda impressa, cartazes em lojas, vitrines, filme) de marcas de varejo (Casas Bahia, Lojas Marisa e Supermercados Extra, Paola da Vinci, Giorgio Armani, Blue Man) e de revista (Máxima) posicionadas para os diferentes estratos sociais. O critério para escolha das marcas foi a clara remissão às classes de interesse.

O objetivo destas imagens, no contexto deste trabalho, é o de apenas constituírem exemplos e ilustrações para a utilização dos conceitos aqui propostos e não o de serem submetidas a uma análise protocolar ou formal. Far-se-ão algumas considerações a título exploratório acerca dessas representações, num breve exercício contemplativo direcionado aos seus efeitos interpretativos.

\subsection{Consumo de inserção - cores e festa}

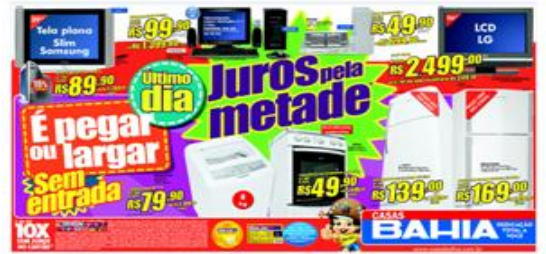

Fig. 1- Folheto de promoções Casas Bahia

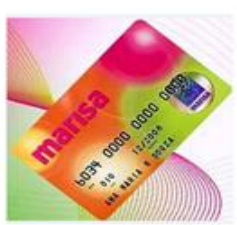

Fig. 2- Cartão Marisa

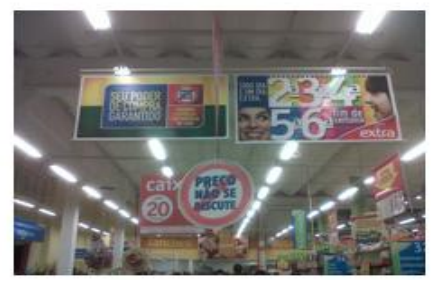

Fig. 3 - Interior de loja Extra Perto

A felicidade de poder consumir está estampada em anúncios que festejam a promoção e a compra a um bom preço (Figura 1), no cartão que possibilita o parcelamento a médio e longo prazos (Figura 2), no interior da loja, que lembra no texto do cartaz que os presentes têm poder de compra e, assegura-lhes o exercício dessa conquista (Figura 3).

É possível salientar nesse conjunto de representações, a presença das cores vivas e a fartura de elementos que preenchem todo o espaço. Esses elementos remetem à alegria, à fartura e à ausência de lacunas. Chegam mesmo a sugerir extravagância e algum exagero. Esses elementos e efeitos sugeridos estão muito alinhados com a condição do consumo de inserção: de preenchimento de necessidades básicas e emocionais a partir do consumo de valores materializados nos produtos; e ao mesmo tempo de negação da escassez deixada no passado. 
O consumo, o gosto, a ponte e a cerca: um estudo exploratório sobre gosto e referências estéticas em propagandas dirigidas à baixa renda

de Jôse Fogaça

A título ilustrativo, buscando enfatizar algumas distinções em relação aos varejos e marcas destinados às classes $\mathrm{A}$ e B, é interessante observar que, ao contrário da exaltação da promoção verificada na comunicação realizada por estas marcas destinadas à baixa renda, as marcas de luxo e destinadas às classes $\mathrm{AB}$ costumam tratar as promoções com muita discrição, na verdade, quase as escondem.

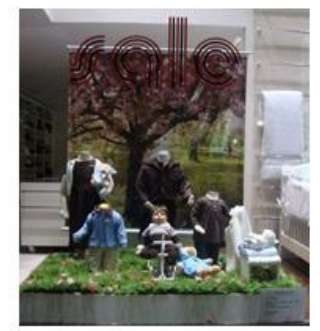

Fig. 4 - Paola da Vinci Jardins

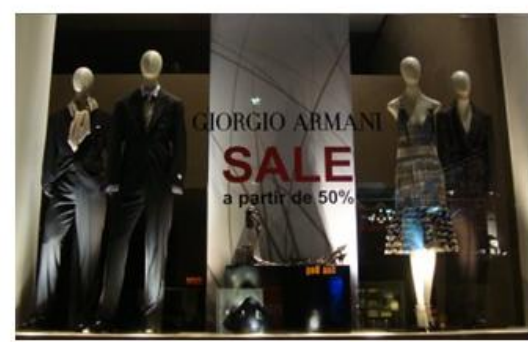

Fig. 5 - Georgio Armani Jardins

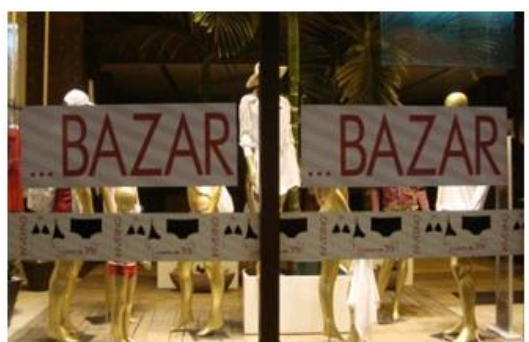

Fig. 6 - Blue Man Jardins

$\mathrm{Na}$ figura 4, acima, é possível verificar uma vitrine em que a informação de que a loja está em liquidação aparece quase mimetizada ao cenário e é suavizada pelo termo em inglês sale, que também é utilizada pela marca Giorgio Armani, na vitrine sem nenhum sinal festivo, ao contrário, carregada de sobriedade, representada na Figura 5. A Figura 6 exemplifica mais um eufemismo correntemente utilizado para as promoções de marcas de prestígio, o "bazar" e utiliza um recurso também recorrente que á cobertura de parte da vitrine em referência a uma tarja, lembrando uma proibição. Promoção para estas marcas, é quase uma vergonha a ser escondida.

\subsection{Consumo de ascensão - múltiplas conquistas}

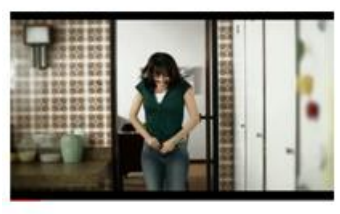

Figura 7

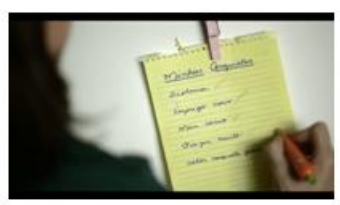

Figura 8

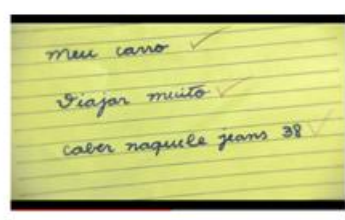

Figura 9

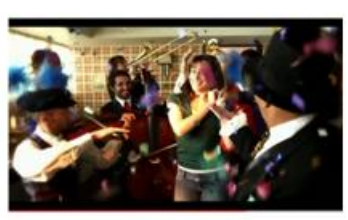

Figura 10

Lançada pela Editora Abril para a mulher da nova classe C, a Revista Máxima foi posicionada para ocupar a lacuna que havia entre as revistas Ana Maria - a "Cláudia da classe baixa" - e a própria Cláudia, tradicionalmente destinada às classes AB. 
O consumo, o gosto, a ponte e a cerca: um estudo exploratório sobre gosto e referências estéticas em propagandas dirigidas à baixa renda

de Jôse Fogaça

O filme de lançamento da revista, intitulado Múltiplas Conquistas, tem o seguinte enredo: a protagonista, em sua cozinha clean com detalhes "retrô", está feliz com o fato de conseguir fechar a calça jeans que está vestindo (Figura 7); em seguida, vai até a porta da geladeira onde faz um check list das suas conquistas. Já estavam ticados: o diploma, o emprego novo, o carro, e o item "viajar muito" (Figura 8); há um close no último item "caber naquele jeans 38", que está sendo ticado no momento (Figura 9); ela é surpreendida pela aparição repentina de uma banda de música muito barulhenta e por uma chuva de papel colorido (Figura 10); a locutora diz, enquanto imagens detalhadas da revista são mostradas: “Comemore cada notícia, ela é sua, ela é o máximo! Chegou Máxima, a Revista da Abril que fala de beleza, moda, dieta e muito mais. Máxima, com você em cada conquista. Por apenas $\mathrm{R} \$ 4,50$.

Esta propaganda traz diversos elementos emblemáticos do conceito de consumo de ascensão, vejamos abaixo.

$\mathrm{O}$ estilo da casa e o da protagonista não remetem em nada à baixa renda. A casa tem referências estéticas de classe $\mathrm{AB}$ : linhas retas e detalhes retrô expressam modernidade, mas, ao mesmo tempo, a expressão maior é de simplicidade, ou de uma casa de família que guarda alguns utensílios e detalhes decorativos do passado.

O estilo e a roupa da protagonista são básicos, jovens e sem exageros, que podem ser usados tanto pelas classes $\mathrm{AB}$ quanto pelas $\mathrm{CDE}$.

A lista de conquistas confirma que a protagonista já está bem inserida na sociedade, já tem tudo o que pode representar estabilidade e segurança (já é formada, tem trabalho e carro) e ainda por cima já viajou muito, o que significa que ela tem também valores e hábitos mais associados à classe alta. A preocupação com a estética (emagrecer e caber no jeans) é mais um sinal de que ela está num patamar superior de prioridades que há muito ultrapassou o das necessidades básicas.

O elemento caracterizador de que ela não é uma pessoa que nasceu numa posição social superior, é a evidência de que ela foi conquistando tudo isso aos poucos, passo a passo, num processo que foi da satisfação das necessidades mais fundamentais para a satisfação de desejos menos funcionais relacionados à cultura de classes superiores.

A última parte do filme traz a festa, o colorido e o exagero, elementos típicos das classes baixas, como já visto, aludindo à expressão da alegria, um valor positivo da pobreza, que por isso pode e deve ser lembrado. 
O consumo, o gosto, a ponte e a cerca: um estudo exploratório sobre gosto e referências estéticas em propagandas dirigidas à baixa renda

de Jôse Fogaça

Ao final deste exercício pode-se concluir que as propagandas analisadas continham elementos característicos para comunicar-se com os distintos públicos de novos consumidores brasileiros, trabalhando de diferentes maneiras o consumo de inserção e o consumo de ascensão. Esse fato nos sugere que a propaganda destinada a esse mercado se serve das referências culturais dos diferentes estratos buscando a comunicação adequada e exitosa. Entender como e em que medida isso ocorre e quão exitoso é esse processo coloca-se então como objetivo para um próximo trabalho.

\section{CONSIDERAÇÕES FINAIS}

Este texto teve por proposta iniciar uma discussão sobre existência de particularidades no gosto dos consumidores de baixa renda e sua repercussão no mundo da propaganda. Levantaram-se questões acerca do significado da entrada no mundo do consumo e da ascensão social através da aquisição de bens materiais e de valores culturais, construindo-se dois conceitos e propondo-os como tipos ideais para análises do tema: consumo de inserção e consumo de ascensão.

Como propositor de discussão e debate, este trabalho não se esgota aqui, mas faz das lacunas abertas e das perguntas propostas novos pontos de partida a serem objetos de aprofundamento em novos trabalhos.

\section{REFERÊNCIAS BIBLIOGRÁFICAS}

BAUMAN, Z. Vida para Consumo: a transformação das pessoas em mercadorias. Rio de Janeiro: Ed. Zahar, 2008.

CALDAS, W. Utopia do Gosto. São Paulo: Ed. Brasiliense, 2009.

CETELEM BGN. O Observador Brasil 2011. São Paulo, 2011. Disponível em http://www.cetelem.com.br/portal/Sobre_Cetelem/observador.shtml

DOUGLAS, M. \& ISHERWOOD, B. O Mundo dos Bens: para uma antropologia do consumo. Rio de Janeiro: Ed. UFRJ, 2009.

FUNDAÇÃO GETÚLIO VARGAS. Os Emergentes dos Emergentes: reflexões globais e ações locais para a nova classe média brasileira. Rio de Janeiro, 2011. Disponível em http://cps.fgv.br/PT-br/brics 
O consumo, o gosto, a ponte e a cerca: um estudo exploratório sobre gosto e referências estéticas em propagandas dirigidas à baixa renda

de Jôse Fogaça

MARTINS, J. R. F. Em Cena, o Consumo: obscurecimento e centralidade.In: II PROPESQ - ENCONTRO DE PESQUISADORES EM PUBLICIDADE E PROPAGANDA. Trabalho apresentado. São Paulo: CRP/ECA/USP, 2011. http://www.eca.usp.br/propesq

McCRACKEN, G. Cultura \& Consumo: novas abordagens ao caráter simbólico dos bens e das atividades de consumo. Rio de Janeiro: Ed. Mauad, 2003.

PEREZ, C. Signos da Marca: expressividade e Sensorialidade. São Paulo: Ed.Pioneira Thomson Learning, 2004.

\section{CRÉDITOS DAS IMAGENS}

Figura 1: http://www.unistudio.com.br

Figura 2: http://www.digitei.com/cartao-marisa-fatura

Figura 3: interior de loja fotografado pela autora

Figuras 4, 5 e 6: http://vitrinerg.blogspot.com

Figuras 7 a 10: Like Filmes http://www.youtube.com/watch?v=m-ItEmTrO8M

Artigo recebido: 03/2012

Artigo aprovado: 06/2012 